\title{
Why we need integrative medicine
}

\author{
Paolo Roberti di Sarsina $\cdot$ Ilaria Iseppato
}

Published online: 19 February 2011

(C) European Association for Predictive, Preventive and Personalised Medicine 2011

\begin{abstract}
Over the last few years the scientific debate on Non Conventional Medicines and their integration with the academic or dominant medicine in our western society has activated a cultural transformation process. This article discusses the main reasons of the need for an integration between the supposed only scientific, mainstream medicine and other cheaper, more holistic, more person-centred expertise.
\end{abstract}

Keywords Integrative medicine $\cdot$ Person-centred medicine $\cdot$ Mainstream medicine $\cdot$ Complementary and alternative Medicine

\section{Dear Editor,}

"Scientific" or Mainstream Medicine (MM) seems at long last to be losing its absolute value in the western world. The BSE (bovine spongiform encephalopathy) problem between Japan and the USA in 2004 was just one example of politicians bandying the term "scientific judgment" in a way that suggests it has really come to conceal the uglier concept of political judgment. Yet conventional doctors too have shown signs of impatience with the rigid doctrines of

P. Roberti di Sarsina $(\square)$

Observatory and Methods for Health, Department of Sociology

and Social Research, University of Milano-Bicocca,

Milan, Italy

e-mail: paolo.robertidisarsina@unimib.it

I. Iseppato

University of Bologna,

Bologna, Italy

e-mail: ilaria.iseppato@gmail.com

Present Address:

P. Roberti di Sarsina

Via Siepelunga, 36/12,

40141, Bologna, Italy western medicine as practised in most of the second half of the twentieth century. A rearguard attempt has been made by MM to maintain absolute authority in the last twenty years, in the form of the Evidence-Based Medicine (EBM) movement.

In this regard, EBM is supposed to exclude trial and error or hit-and-miss methods. Three important aspects of EBM are generally described as 1) medical knowledge and clinical skill, 2) (scientific) evidence through clinical investigations, and 3) patient preferences. However, these fundamental concepts contain a paradox. First, science will always need to be open-minded about new experience if it is to continue on empirical lines (though empiricism - induction and deduction forging theory on the basis of experiment- is inevitably hit-and-miss to begin with). Secondly, patient preferences are multifactorial and multidirectional, and vary according to changing personal desires. A scientific evaluation of patient preferences cannot be done in terms of contemporary common sense [1]. For example, quality of life (QOL), which forms part of wellbeing, has crept into conventional assessment criteria, but is very much a personal value judgment belonging to an area that fits the "alternative" better than the mainstream approach.

Even in the first/second decade of the new century, MM remains emphatically disease-centred and not patientcentred, still less person-centred [2,3]. It has made great progress by focusing on organs and systems, to the exclusion of the whole man. The wisdom of "science" is filtered "top down" with astonishingly little expectation that the patient be responsible for his own health. In this way the doctor carries a false burden of responsibility and becomes vulnerable to litigation (since insurance, too, knows how to dress up in "scientific" colours). MM has done a lot in specific areas of prevention (mass screening for mammary cancer, colon cancer, etc.) but in the main pays no more than lip service to prevention, being forced to spend its energies patching up the consequences of bad environment and bad lifestyles [4]. 
Death is another blind pot of MM. Far from considering that it has a meaning, doctors look on death as a failure. It is with great reluctance that palliative care has been conceded a small part of the resources that it requires (especially human resources: palliative care is too often seen as a career blind alley). Though much, again, has been achieved here (against the better judgment of the "scientist", one sometimes feels), there is little recognition (except by a grateful public) that this branch of medicine stands in the noblest tradition of doctoring: being able to ease the inevitable end.

The distillation of scientific and medical expertise from on high cuts less and less ice in an age like the present that perceives official medicine to be failing to deliver. Part of this perception is due to people's greater access to information, part to the obvious fact that the cost of the health system is unsustainable even in the richest countries and will spiral out of all control unless we change some of our demands on it. There is also natural suspicion that when costs soar, medicine will cease to be "inclusive" or "equitable" and end in social injustice [5].

As a corrective to this so far largely negative assessment of public health today, it must be added that the physicians of the health system deserve a lot more sympathy than they tend to get. That MM is failing is probably the wrong phrase: it is perceived to be failing, partly for the wrong reasons. People feel that they are well-informed but are actually victims of over- or misinformation. Bad news sticks and the picture given by the press is far too slanted towards misfortune to be taken as a reliable vision of any situation. Nowhere is this more true than in public health. Again, people have been through a period in which extravagantly funded medicine brought a peak in social services. The latter are now perceived to be waning as the real cost of the service cuts in. The very successes of late twentieth-century medicine raised people's expectations beyond all reason. In the wake of those successes (e.g. in dialysis and transplantation), doctors are being asked to tackle categories of patient that were ruled out in the past (e.g. the extension of kidney dialysis to diabetics and the very old). Inevitably, the failure rate goes up and the facilities are swamped.

Doctors are also subject to a series of intolerable "double binds". They are held responsible for keeping the patient alive or healthy when death is both inevitable and universal, while the patient is free to incur avoidable complaints by a disastrously inappropriate lifestyle. The patient is not held responsible for causing the situation of risk and the work/ resources spent in remedying it, but the doctor may be prosecuted for the least lapse in efficiency. Again, doctors are often forced to stay within the strait-jacket of EBM and government-recognised treatments or peer-recognised guidelines, on penalty of litigation. This reinforces the reductive approach and cramps the scope for intuitive flair. Lastly, doctors are under pressure to prescribe the most expensive tests and treatments at a period when administrations are hounding them to cut costs. Anyway, the patient has probably been on the internet and demands "the best".

But sympathy with the lot of the average GP or hospital doctor should not blind us to the fact that much is wrong with the whole paradigm of modern western medicine. Paradigms have a habit of changing when the time is ripe. This is also something to do with people's perceptions, which are affected by the press but even more eloquently and memorably by a film/case like "Patch Adams" which sums up much of what we have been saying.

MM is not going to wither away, whatever the strength of the critique or the unsustainable cost. But it clearly does need integrating with other cheaper, more holistic, more person-centred expertise. Integrative Medicine (IM) fills this gap [6-9]. It works with the mainstream, supplementing its deficiencies, bearing some of the brunt, redressing the emphases. It sets out to offer:

a) a gamut of traditional, complementary and alternative approaches for the well-informed "patient" to choose from. GPs moving with the times are already in a position to guide their patients here as in the health system at large (thus performing a kind of "gatekeeping" service for those who fear the Trojan Horse of "lunacy"). By "tradition", note that one here means traditions other than that of western medicine itself: traditions whose practices are designed to promote mental, physical and spiritual wellbeing, based on beliefs stemming from before western "scientific" biomedicine;

b) an approach to the whole person, including the full range of physical, emotional, mental, social, spiritual and environmental influences that affect a person's health. It engages the whole person in the attainment of a personalised lifestyle that supports health, not ignoring factors like exercise, love/intimacy/emotional wellbeing which foster resiliency;

c) respect for the so-called patient's right to choose, whilst greatly increasing the demand that he/she live responsibly. Greater choice can help keep hope alive- itself of considerable therapeutic value [10];

d) assessment of the workings of multiple physiological sub-systems concurrently, and in relation to each other, not relying on single markers as evidence of "health";

e) genuine and intrinsic emphasis on prevention and quality of life (in being a person-centred approach);

f) relief to MM in terms of cutting costs and sharing the burden of responsibility to keep people well (the great social money-saver); 
g) a range of choices suited to a multi-cultural system. In a world that feels less and less "western", this will boost the confidence of people from many backgrounds and thus steer them better (among other things) towards mainstream solutions if these should prove indicated;

h) respect for illness and death as meaningful. This is particularly true of traditional medicines. Psychospiritual wellbeing even in the face of incurable or chronic physical disease may enhance the intensity and depth of living. Again, as in the point above, by catering for spiritual aetiologies, traditional healing fits the world-view of many non-western cultures mingling with western societies, as well as those of westerners exploring other spiritual areas (a growing number).

Integrative Medicine, of course, has its own potential shortcomings which must be addressed and if possible obviated. One such is the problem of evaluation. The doctrines of complementary, alternative and traditional medicine (CATM) are not able to be recast in a scientific mould. Evaluation standards from the viewpoint of modern scientific medicine are generally too strict to be accepted here. Scientific medicine was from the beginning in a position to exclude CATM on the grounds that it is not scientific. Strong on personal value judgment including evaluation of QOL based on a whole-person medical record (physical-mental-spiritual-relationship-centred), IM nonetheless has a limited base of biomedical evidence. The paucity of biomedical research has been attributed to the limited number of IM researchers, lack of funding and the unsuitability of empiric-analytical approaches to IM therapies (e.g. difficulty of measuring response to energetic healing or identifying placebo controls in massage and touch therapies). An integrated evaluation model for the study of whole-system healthcare is urgently needed, combining with sociological, anthropological and behavioural research, as well as cellular and molecular biology (participant observation studies, in-depth interviewing, focus-group studies).

It must also be added that IM has a good record for not neglecting the gamut of factors that have important health consequences, such as education, housing, emotional wellbeing and back-up. What it may lack in evaluation models targeting the main symptoms and response, it makes up in attention to the broader picture. It is meant, after all, to be integrative medicine, supplementing deficiencies in the present paradigm.
Lastly, it may be superficial or premature to regard IM as intrinsically cost-cutting. At present its remedies are less prone to exploitation by big business. But they can easily be targeted if the pendulum of public preference swings. It should be a priority to keep the situation this way, if we are to have a real improvement in sustainability. Also, if the shortcomings of IM in terms of testing and evaluation are simply made good by recourse to expensive diagnostic tools, there will be no outright gain in the sustainability of western health. It is probably by changing the public (and doctors') mentality and expectations that one stands the best chance of containing the health budget to sustainable proportions.

Conflicts of interest None.

\section{References}

1. Hollenberg D, Muzzin L. Epistemological challenges to integrative medicine: An anti-colonial perspective on the combination of complementary/alternative medicine with biomedicine. Health Soc Rev. 2010;19(1):34-56.

2. Roberti di Sarsina P, Iseppato I. Looking for a Person-Centred Medicine: Non Conventional Medicine in the Conventional European and Italian Setting. Evid Based Complement Alternat Med. 2011; doi:10.1093/ecam/nep048.

3. Roberti di Sarsina P, Iseppato I. Non Conventional Medicine in Italy: the present situation. European Journal of Integrative Medicine. 2009;1(2):65-71.

4. Woolf SH, Dekker MM, Rothenberg Byrne F, Miller WD. Citizen-Centred Health Promotion. Building Collaborations to Facilitate Healthy Living. Am J Prev Med. 2011;40(1S1):S38-47.

5. Boyer CA, Lutfey KE. Examining Critical Health Policy Issues within and beyond the Clinical Encounter: Patient-Provider Relationships and Help-seeking Behaviours. J Health Soc Behav. 2010;51(S):S80-93.

6. Roberti di Sarsina P. The Social Demand for a Medicine Focused on the Person: The Contribution of CAM to Healthcare and Healthgenesis. Evid Based Complement Alternat Med. 2007;4 (S1):45-51.

7. Roberti di Sarsina P, Iseppato I. Person-Centred Medicine: Towards a Definition. Forsch Komplementmed. 2010;17:277-8.

8. Costigliola V. Healthcare overview: global process of personalisation in medicine. EPMA J. 2010;1:525-8.

9. Mezzich JE, Snaedal J, Van Weel C, Botbol M, Salloum I. Introduction to person-centred medicine: from concepts to practice. J Eval Clin Pract. 2010; doi:10.1111/j.13652753.2010.01606.x.

10. Lee YY, Lin JL. Do patient autonomy preferences matter? Linking patient-centred care to patient-physician relationships and health outcomes. Soc Sci Med. 2010;71:1811-8. 